\title{
The Innovation of Mental Health Education Mode from the Perspective of Positive Psychology
}

\author{
Liangmin $\mathrm{LI}^{1}$ \\ 1. Northeast University STS research center, China, 110004 \\ 2. Liaoning College of Communications, China, 110122
}

\begin{abstract}
How to innovate the working mode of mental health education and improve the practical work effect of education in mental health remains an important issue nowadays. This paper discusses the status of mental health education, explores countermeasures for the psychological problems combined with the theory of positive psychology. The positive psychology attaches importance to the prevention of mental disorders, regards subjective well-being as the core of positive psychological experience, and attaches importance to the building of positive personality traits and innovation of mental health education. For example, education system construction -- the organic combination of the first class and the second class, the consultation system construction -- with warm communication as the focus, and the practical training system construction -- with quality development training as the focus and so on.
\end{abstract}

Keywords-Positive psychology; Mental health education; Mode innovation; The perspective of Positive Psychology

\section{INTRODUCTION}

Statistics of relevant studies show that at present, nearly $30 \%$ of college students are psychologically disadvantaged, which adds a discordant note to the construction of harmonious campus. At present, the mental health problems of college students have shown a trend of diversification and complexity in various universities, which has brought certain challenges to the work of education in school mental health. How to carry out the work of education in mental health effectively? More and more mental health workers of education think deeply. The communist party of China education ministry about print and distribute the college students' psychological health education guidance outline of notice (teach party [2018] no. 41) file explicitly put forward: the psychological health education is to improve the college students' psychological quality, promote the harmonious development of physical and mental health education, is an important part of college talent cultivation system, is also the important content of ideological and political work in colleges and universities. How to innovate education working mode of mental health and improve the effect of education in mental health is an important topic for education teachers in colleges and universities.

\section{THE PSYCHOLOGICAL HEALTH SITUATION}

Each college psychological health education work in China already has a history, but so far, the scientific and professional of psychological health education work is not strong, there is no agreement on some of the basic concept and theory. Especially some parents, teachers and students have no enough attention to the importance of psychological health level. In particular, the school mental health education on the value orientation deviation from the positive psychology orientation of mental health, and fell into a psychological disease prevention and treatment of the pathological psychological orientation.

\section{CONNOTATION OF POSITIVE PSYCHOLOGY AND ENLIGHTENMENT TO PSYCHOLOGICAL HEALTH EDUCATION}

\section{A. Connotation of positive psychology}

As a new research orientation in psychology, positive psychology is marked by the introduction to positive psychology, a paper published by Seligman and Csikzentmihalyi in January 2000. Positive psychology is a revolution in the field of psychology and a new milestone in the development of human society. It is a pessimistic view of human nature, to pay attention to the positive side of human nature, advocating the study of human positive psychological quality, think the purpose of psychology is not only depends on the Human shortcomings and weaknesses, but to pay attention to people's positive emotional experience, inherent in fully excavate potential, constructive force, to help people form the good psychological quality and behavior patterns.

\section{B. The enlightenment of positive psychology to mental health education}

The emergence of positive psychology has changed people's traditional understanding that psychology is only about solving psychological problems and treating psychological diseases. It makes the original one-sided psychology more complete and balanced, injects new vitality into the development of psychology, and makes many research fields of psychology turn to the positive aspect of people. The specific performance as follows:

${ }^{1}$ Liliangmin associate professor Doctoral candidate of Northeastern University Research interests: methodology of scientific and technological creation email:liuyangfree@163.com 
1) Positive psychology attaches importance to the prevention of mental disorders

Positive psychology think prevention than treatment of mental disorders, believes that human beings exist to resist the power of the mental disorders, mental health education need to mobilize the internal force of the human body, rather than merely focus on human own shortcomings and weaknesses, by the excavation, the troubled individual self defence force, can be effectively prevent psychological disorders.

2) Positive psychology regards subjective well-being as the core of positive psychological experience

Influence human psychology to allude to the people themselves are significant, positive psychology focuses on the human positive psychological experience, such as: optimistic, the work of the spirit of ecstasy, happiness and freshness, and the flow. Csikszentmihalyi claims as the main body of the people in the process of creation, to produce the most satisfying experience is called flow.

3) Positive psychology attaches importance to the building of positive personality traits

Positive psychology think that it cannot be separated from people's social environment, the study of positive psychology in isolation, should be examined in the social and cultural ecology system, train and bring up healthy personality, such as: positive personality, self-esteem, decisive ability, good environmental adaptation ability, wisdom, mature defense, self organization, self directed, creativity and talent, and so on. These excellent personality advantages will permeate the whole life space of people and have a long-term impact.

\section{EDUCATION MODEL INNOVATION OF MENTAL HEALTH FROM THE PERSPECTIVE OF POSITIVE PSYCHOLOGY}

From the perspective of positive psychology, education innovates education working mode of mental health in line with the working principles of prevention, warning and assistance, starting from education system, consultation service system and practical activity system.

\section{A. Education system construction -- the organic combination of the first class and the second class}

The prevention work of education of mental health needs to start from the popularization of mental health knowledge, standardize the course setting, strive to realize the organic connection between the first class and the second class, and promote the knowledge of mental health education. By developing and constructing education online courses of mental health, education teaching methods of mental health are innovated, and education teaching forms are constantly enriched. Through the construction of education teaching resource base for mental health, it can realize the organic combination of offline online, experiential activities, behavioral training and other forms, stimulate students' interest in learning, improve the classroom teaching effect and constantly improve the teaching quality.

\section{B. Consultation system construction-with warm communication as the focus}

We will improve institutional building. Through the fourlevel psychological consultation service system construction of school, department, counselor and psychological committee, we will improve the appointment, key feedback and referral system of education and consultation for mental health. We will improve the consulting service system. Provide timely and effective consulting services to students through various forms such as group counseling and individual counseling. Implement classified guidance and teach according to aptitude. In accordance with the principle of confidentiality and in combination with students' thoughts and reality, we will provide accurate and appropriate measures for non-students and students of different majors, and teach them according to their aptitude. Specifically speaking:

1) First-level network: school-level warm communication

Education work center for college students' mental health was set up to coordinate the relationship between various departments and form a joint force, so as to facilitate the smooth development of warm communication among college students and comprehensively improve the implementation of warm communication among college students. Specific measures are as follows: issue relevant documents, clearly implement the guidelines, work objectives, communication outline and specific measures of warm communication, and escort the effective implementation of warm communication through necessary preconditions and policy support. Set up warm communication leading group, responsible for the warm communication work of the whole school organization leadership and coordination supervision work. To study, plan and formulate implementation plans and supervision plans of warm communication, guide departments to conduct warm communication among college students, and evaluate the effectiveness of warm communication among students.

\section{2) Second-level network: departmental warm} communication

Each department sets up education work leading group for college students' mental health at the department level to guide and deploy the warm communication work of college students at the department level. In combination with the daily management of education, they actively carry out the prevention work of students' psychological crisis. Specific measures are as follows: a sweet communication the department work plan, guidance of learning class, counselor, tutor, director of the GongBan sweet communication work, grasp the students' psychological dynamics, build sweet communication archives, timely report to the college students' mental health education centre to prevent, warning students group, is advantageous for the mental health education center lock object of psychological crisis intervention, in the psychological crisis assessment and intervention, etc. 
3) Third-level network: warm communication between friends

Peer warm communication subject is departments psychological committee member, by deep between classmates system training them in a timely manner, take the initiative to care about the psychological status of the classmate, after learning that the students have a psychological turmoil or crisis event occurs, take timely support measures, such as peer coaching and mentoring specific student group for help instructors, class teacher and psychological counseling center, etc., thus avoid psychological crisis.

In addition, under the guidance of the principle of combining creating atmosphere and reforming environment, we will continue to refine the work at three levels. Secondly, it focuses on cultivating students' resilience against setbacks, which is the key to warm communication. Third, the cultivation of students' good psychological quality education is the key to warm communication. In addition, we should actively and diligently build a high-level team of warm communication teachers, and ultimately protect the overall improvement of warm communication work.

\section{Practical training system construction -- focusing on quality development training}

Education training system for mental health was set up around socialist core values. Quality development training is an emerging experiential learning method for modern people and modern organizations. The quality development training is mainly through the elaborately designed development training project, which stimulates the individual potential and enhances the team's vitality, cohesion and creativity, so as to achieve the training goal of honing the will, cultivating the sentiment, improving the personality and melting the team.

1) Education quality development training and construction target based on social quality training

Higher vocational students' social quality training for freshman students, guided by the socialist core values, the surrounding environment adaptability, interpersonal skills, career planning ability, ability to learn, gratitude, such as module, compile corresponding diathesis developing training programs and training students' good psychological quality and self-esteem, self-love, self-discipline, good strength of character, in order to better adapt to college life;

2) Education quality development training and construction target based on occupational quality training

Higher vocational students' professional quality training for sophomore and junior students, guided by professionalism, around the learning efficiency, innovation ability, team cooperation ability, good faith consciousness cultivation, and the pressure relief, such as module, compile corresponding diathesis developing training programs and training students have good professional ethics, strong sense of responsibility and professional dedication; Train students to understand corporate culture and corporate spirit, and comply with corporate standards; Cultivate students' perseverance, improve their ability to cope with competition and setbacks, and develop a good style of hard work.
3) Quality development training adopts hierarchical and progressive training

According to the social quality training quality development training construction target and vocational quality training development and development training target, the establishment of quality development training program for students of different grades should be differentiated analysis, quality development training should be graded and advanced, and evaluation criteria should be established around different quality development training.

4) The application of quality development training in improving college students' mental health level

Application of environmental adaptation. In order to adapt college students to college life as soon as possible, colleges and universities will use three months, half a year, or even one year to launch new students' education activities. Group counseling can help students get to know each other as soon as possible and shorten the distance between them. Both in the mental health education class and in the group counseling after class, we can use the group psychological counseling to help students to get together as soon as possible, strengthen communication, speed up the process of students to understand the learning environment and living environment, and alleviate the psychological pressure brought by the new environment.

Application of emotion management. Under the influence of multiple pressures, such as grades, relationships, friendship and employment, some college students are prone to adverse emotional experiences such as anxiety and depression. In addition, they are not correct in their self-evaluation, and they are also prone to conceit or inferiority. Is one of the advantages of group psychological guidance in real experience, positive participation, make the members self-understanding, understanding of others, to understand their own emotions, watch the mood at the same time, in contrast, their emotional wrong, in order to perceive our mood changes, timely control the bad mood, reasonable use way of venting of undesirable $\operatorname{mood}[1]$.

Use of interpersonal relationship management. Interpersonal communication is the process of exchanging ideas, feelings and information between people. The psychological relationship between people formed on the basis of communication is interpersonal relationship. College students come from different regions. The differences between north and south China, eating habits and sleeping habits make some college students encounter many problems in interpersonal communication. When interacting with others, they show signs of shyness, rapid heartbeat, wheezing, blushing, incoherent, inarticulate and other communication barriers. Group psychological counseling provides a communication platform for students. Through the guidance of the organizer, students can realize the key problems in interpersonal communication, correct their attitude, try to learn to establish good interpersonal relations with others in the experience, and achieve a harmonious relationship with classmates.

Application of improving team cohesion. One of the important applications of group psychological counseling is to improve the cohesion of students. For an unfamiliar organization, for example, there is strangeness among class 
members after the first enrollment. The newly established class committee, school department student union, school student union and other formal organizations, interest groups, associations and other informal organizations, etc. In the early stage of operation, the cohesion of the organization is not strong, and it is difficult to coordinate all kinds of activities immediately or even have contradictions. Through group psychological counseling, taking cohesion improvement as the counseling theme, and by means of painting, sand table, etc., students can be motivated to help students to strengthen mutual understanding, learn to put themselves in others' shoes, learn to plan as a whole, learn to coordinate, and finally achieve the goal of cohesion improvement.

\section{CONCLUSIONS}

The guide of positive psychology, mental health education to realize the education teaching, practical activity, consulting services, prevention and intervention of "four one" mental health education work mode, adhere to the heart and the moral education unifies, to strengthen the humanistic care and psychological counseling, standardize and develop the mental health education and consulting service, better adapt to and meet the demand of students' psychological health education services, improve the psychological health education work.

\section{ACKNOWLEDGMENTS}

This paper is the 2017 a social and scientific planning item of Liaoning province. (The ideological and political special project of colleges and universities): the practical application of group psychological counseling in warm communication. Project No. (L17DSZ010)

\section{REFERENCES}

[1] Chang hiuli, Yu haitao. Research on the influence of "extension training" on college students' mental health [J]. Journal of henan education university: nature science edition, 2005, 14 (4). (In Chinese)

[2] Wang quanjun. An empirical study on the effect of expanding training teaching on college students' mental health and class cohesion [J].Journal of wuhan sports university,2011,45(8). (In Chinese)

[3] Zhangwulong, Zhou huijuan. Development of training teaching has an impact on improving the cooperative ability of college students [J]. Journal of Xi'an sports university, 2006(2). (In Chinese)

[4] Chen hao. Some thoughts on psychological health education curriculum reform [J]. Journal of changjiang university of technology, 2009 (4). (In Chinese) 